\title{
Article \\ A Short-Time Approach for Fatigue Life Evaluation of AISI 347 Steel for Nuclear Power Energy Applications
}

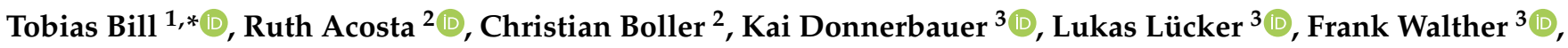 \\ Klaus Heckmann ${ }^{4}$, Jürgen Sievers ${ }^{4}$, Tim Schopf ${ }^{5}$, Stefan Weihe ${ }^{5}$ and Peter Starke ${ }^{1}$
}

1 Department of Materials Science and Materials Testing (WWHK), University of Applied Sciences Kaiserslautern, Schoenstraße 11, D-67659 Kaiserslautern, Germany; peter.starke@hs-kl.de

2 Chair of Nondestructive Testing and Quality Assurance (LZfPQ), Saarland University, Am Markt 4, D-66125 Saarbrücken, Germany; ruth.acosta@uni-saarland.de (R.A.); christian.boller@gmx.de (C.B.)

3 Chair of Materials Test Engineering (WPT), TU Dortmund University, Baroper Str. 303, D-44227 Dortmund, Germany; kai.donnerbauer@tu-dortmund.de (K.D.); lukas.luecker@tu-dortmund.de (L.L.); frank.walther@tu-dortmund.de (F.W.)

4 Gesellschaft für Anlagen und Reaktorsicherheit (GRS) gGmbH, Schwertnergasse 1, D-50667 Köln, Germany; klaus.heckmann@grs.de (K.H.); juergen.sievers@grs.de (J.S.)

5 Materials Testing Institute (MPA), University of Stuttgart, Pfaffenwaldring 32, D-70569 Stuttgart, Germany; tim.schopf@mpa.uni-stuttgart.de (T.S.); stefan.weihe@mpa.uni-stuttgart.de (S.W.)

* Correspondence: tobias.bill@hs-kl.de; Tel.: +49-631-3724-2354

check for

updates

Citation: Bill, T.; Acosta, R.; Boller,

C.; Donnerbauer, K.; Lücker, L.;

Walther, F.; Heckmann, K.; Sievers, J.;

Schopf, T.; Weihe, S.; et al. A

Short-Time Approach for Fatigue Life Evaluation of AISI 347 Steel for

Nuclear Power Energy Applications.

Appl. Sci. 2021, 11, 11405. https://

doi.org/10.3390/app112311405

Academic Editor: Ricardo Branco

Received: 29 October 2021

Accepted: 24 November 2021

Published: 2 December 2021

Publisher's Note: MDPI stays neutral with regard to jurisdictional claims in published maps and institutional affiliations.

Copyright: (C) 2021 by the authors Licensee MDPI, Basel, Switzerland. This article is an open access article distributed under the terms and conditions of the Creative Commons Attribution (CC BY) license (https:// creativecommons.org/licenses/by/ $4.0 /)$.

\begin{abstract}
AISI 347 austenitic steel is, as an example, used in nuclear energy piping systems. Piping filled with superheated steam or cooled water is particularly exposed to high stresses, whereupon local material properties in the pipes can change significantly, especially in the case of additional corrosive influences, leading to aging of the material. In the absence of appropriate information, such local material property variations are currently covered rather blanketly by safety factors set during the design of those components. An increase in qualified information could improve the assessment of the condition of such aged components. As part of the collaborative project "Microstructure-based assessment of the maximum service life of core materials and components subjected to corrosion and fatigue (MiBaLeB)", the short-time procedure, StrainLife, was developed and validated by several fatigue tests. With this procedure, a complete $\mathrm{S}-\mathrm{N}$ curve of a material can be determined on the basis of three fatigue tests only, which reduces the effort compared to a conventional approach significantly and is thus ideal for assessing the condition of aged material, where the material is often rare, and a cost-effective answer is often very needed. The procedure described is not just limited to traditional parameters, such as stress and strain, considered in destructive testing but rather extends into parameters derived from non-destructive testing, which may allow further insight into what may be happening within a material's microstructure. To evaluate the non-destructive quantities measured within the StrainLife procedure and to correlate them with the aging process in a material, several fatigue tests were performed on unnotched and notched specimens under cyclic loading at room and elevated temperatures, as well as under various media conditions, such as distilled water and reactor pressure vessel boiling water (BWR) conditions.
\end{abstract}

Keywords: fatigue life evaluation; non-destructive testing; destructive testing; nuclear safety; AISI 347; integrity assessment; material characterization; aged material conditions; fatigue lifetime calculation

\section{Introduction}

As part of the ongoing collaborative project "MiBaLeb" the fatigue behavior of the metastable austenitic steel AISI 347 (1.4550) is being characterized under various boundary conditions relevant to nuclear power engineering. AISI 347 steel is used in pipes, volume control, reactor water purification, feed water system and other components of German nuclear power plants (e.g., in current light-water reactors (LWR) plants) in a temperature range up to $350^{\circ} \mathrm{C}$. 
Non-destructive testing (NDT) techniques offer great potential for detecting the microstructural degradation that precedes micro crack formation. However, this potential has not been sufficiently explored when it comes to the fundamentals of quantitatively characterizing the material behavior under static, cyclic, as well as any combinations of thermal and corrosive loading using NDT, which might provide an insight into the interactions between an NDT-based measurement signal and a material's microstructure. The MiBaLeb project claims to determine valuable results in this regard and to provide those results for future application. The aging-related degradation processes affect the plant components individually, resulting from both static and dynamic loading, and this in combination with thermo-mechanical loads. In piping systems of light water reactors, the temperature range from 200 to $330^{\circ} \mathrm{C}$ is of particular interest, which is mainly based on the run-up and run-down processes of a power plant system [1].

Evidence that the degradation level $D$ (traditionally expressed as "damage") can be defined within certain limits $(0 \leq D \leq 1)$ is currently provided by structural mechanical analyses. For this purpose, fatigue analyses distinguish between elastic, simplified elastoplastic and general elasto-plastic cases. Elasto-plastic finite element analyses of model transients have been proposed as an example to determine the real damage level very precisely [2]. In addition, probabilistic methods are used to describe the uncertainties arising with respect to the loads applied and scatter in the material properties to be expected. These methods are prescribed in the regulations of the respective countries where the plants are operated. In this context, the Gesellschaft für Anlagen und Reaktorsicherheit (GRS) has developed the probabilistic analysis tool PROST (PRObabilistic Structure calculation) for the determination of structural reliability and durability, respectively, to be used for the assessment of piping and vessels [3] This allows crack formation, as well as crack behavior, to be determined in relation to various damage mechanisms. Probabilistic investigations of the leakage and fracture of piping components as a function of the operating time can also be carried out with PROST [4-6].

The design of cyclically loaded components is usually based on the service life derived from S-N curves. To generate such curves, many fatigue tests are traditionally required, which makes the process time-consuming and costly. The basics of the traditional service life evaluation principles are provided by the application of damage accumulation hypotheses, such as those according to Palmgren and Miner [7,8]. However, experimental investigations have shown that, especially in the case of additional corrosive (chemical) loading, the assumption of linear accumulation damage being related to stresses and strains applied is only valid to a limited extent. Again, safety factors are the current solution to cover the resulting inaccuracies and uncertainties [9].

Short-time evaluation procedures (STEP) developed in recent years need to be mentioned in this context, including the StrainLife method to be considered here, which can reduce the number of fatigue tests, as well as the time and cost required by more than $90 \%$. Many of those STEP methods are based on generalized Morrow and Basquin equations, e.g., in a combination of strain (SIT) or load (LIT) increase tests and stress or strain-controlled constant amplitude tests (CAT), which enable the evaluation of S-N curves for the materials investigated. The validation of the STEP has already been successfully performed on various light metal alloys and steels in different heat treatment conditions, including the determination of scatter bands for different fracture probabilities [10-15].

In addition to conventional mechanical stress-strain measurements, STEP for determining S-N curves can also take advantage of NDT-based techniques and parameters, which may rely on temperature and electrical resistance, but also on magnetism or ultrasound. These methods may, therefore, provide a potential for detecting and tracing the damage evolution in a non-invasive way. Electrochemical parameters based on the corrosion potential [16-19] or the corrosion current density $[18,20]$ can also be used for damage characterization in corrosion fatigue tests. Microstructural changes, such as the formation of slip bands or the crack initiation/propagation on the material's surface, can be correlated 
with these measured variables [20]. This has been successfully shown for different materials allowing the progression of corrosion fatigue damage to be described [21,22].

The STEP mentioned above was extended in "MiBaLeb" to include aspects, such as strain control, thermo-mechanical loading and corrosion, which are important aspects for the design of piping systems in nuclear facilities, and this in view of allowing a transition between component behavior as well as material properties and vice versa.

\section{Materials and Methods}

Mechanical stress-strain measurements within cyclically loaded total strain-controlled constant amplitude (CAT) and strain-increase tests (SIT) in air, as well as under distilled water media conditions, were performed using an extensometer with an initial length of $L_{0}=89 \mathrm{~mm}$, mounted on the specimen shafts and measuring the deformation, allowing the resulting total strain amplitude $\varepsilon_{a, t}$ to be determined during the fatigue test. Since this extensometer setup measures deformation along the minimum cross-section and the transitions of the specimen's shafts, the calibration to the strain values within the minimum cross-section is essential. A second extensometer was, therefore, applied in the minimum cross-section, allowing a correlated total strain amplitude $\varepsilon_{a, t, c o r}$ to be used as the controlled value. All fatigue tests were performed with a strain ration of $R=-1$ and a constant strain rate of $\varepsilon_{a, t, c o r}=4 \times 10^{-3} / \mathrm{s}$ using triangular strain-time functions.

Additionally, a special in situ cell for fatigue tests performed in distilled water was developed, allowing additional measurement techniques to be included (Figure 1a). It should be noted that in tests with AISI 347 steel, distilled water does not cause any corrosion effects on the material. However, comprehensive, well-adhering oxide layers are formed, which are locally broken up due to surface damage, e.g., by micro cracks, followed by macro cracking along the further process. In this context, the electrochemical open-circuit potential $\left(E_{O C P}\right)$ can be used to describe these effects occurring at the material's surface on the specimen, and thus enables further fatigue-related damage mechanisms to be separated. For this purpose, a pump-driven water circuit is used to circulate the water through the cell, and a thermostat continuously cools the medium to a temperature of $22{ }^{\circ} \mathrm{C}$. For electrochemical measurement, a reference electrode (silver chloride) and a counter electrode (graphite) are used in the cell, and the fatigue specimen serves as the working electrode.

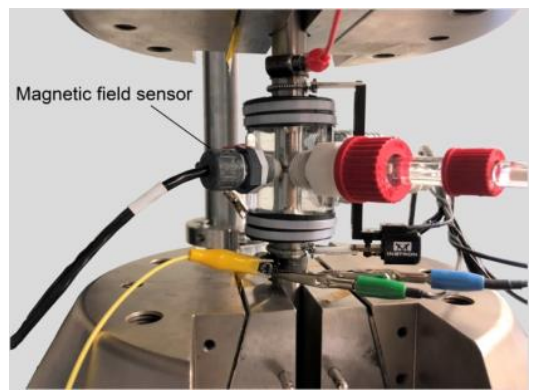

(a)

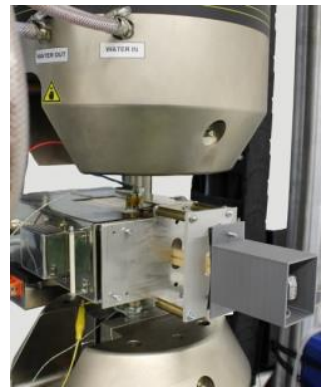

(b)

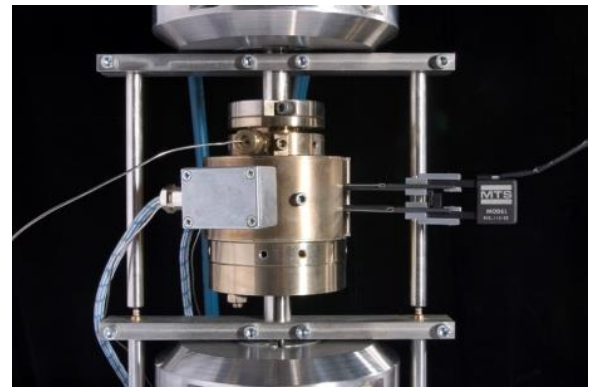

(c)

Figure 1. Experimental setup at (a) room temperature in distilled water; (b) higher temperatures; (c) reactor pressure vessel boiling water conditions.

Fatigue tests at elevated temperatures up to $300{ }^{\circ} \mathrm{C}$ were carried out using a custombuilt furnace for the servo hydraulic testing machine and a high-temperature extensometer (Figure 1b).

Furthermore, fatigue tests were performed under reactor pressure vessel boiling water (BWR) conditions at $70 \mathrm{bar}$ and $240{ }^{\circ} \mathrm{C}$ in a specially designed autoclave (Figure 1c). The high-temperature water used in the fatigue tests was provided by a water treatment plant and had a conductivity of about $0.055 \mu \mathrm{S} / \mathrm{cm}$. The impurities due to chloride ions were generally below $5 \mu \mathrm{g} / \mathrm{kg}$, which is in accordance with the VGB guidelines [23] for the quality of reactor water in BWR plants in normal operation according to the guidelines. 
The oxygen content in the fluid was set to $400 \mu \mathrm{g} / \mathrm{kg}(0.4 \mathrm{ppm})$, which is the upper limit for BWR plants and is mainly used in international laboratory studies to simulate BWR conditions.

To measure the change in electrical resistance, a high constant current $(I=8 \mathrm{~A})$ was applied to the specimens using a DC potential probe. During loading, the change in voltage and the thereon-dependent change in electrical resistance along the specimen was measured via wires mounted at the transitions between the gauge length and the shafts using adapted copper clamps and connected to a voltage measurement card with a maximum voltage range of $\pm 500 \mathrm{mV}$. The change in electrical resistance depends, on the one hand, on the change in specimen geometry (which can be neglected for a load ratio of $R=-1$ ). The deciding factor, however, is the change in the specific electrical resistance, from which direct conclusions can be drawn about the change in the defect density of the materials.

During the fatigue tests, a magnetic field sensor was used to record changes in the tangential magnetic field strength due to the progressively forming ferromagnetic phase fractions, which is generated based on the deformation-induced $\alpha^{\prime}$-martensite formation of the AISI 347, as well as on microstructural changes due to dislocation reactions, as well as crack initiation and propagation processes at different load levels. $\varepsilon$-martensite could also be formed, but this is not detectable due to its paramagnetic properties. The probe consists of a Hall sensor encapsulated with epoxy resin in a PTFE housing. For magnetization, a constant direct current was applied to the specimen. Magnetic measurements up to elevated temperatures of about $200{ }^{\circ} \mathrm{C}$ can be realized without affecting the sensor functionality (see Figure 1a).

Microstructural investigations of the metastable austenitic steel AISI 347 (1.4550) carried out along the minimum cross-section of the bar material showed significant microstructural variations in the individual cross-sectional areas. After etching with V2A etchant and subsequent optical microscopy examinations, as well as crystallographic analyses using electron backscatter diffraction (EBSD) measurements (Figure 2a) on the unetched sample, a square region consisting of an inhomogeneous multiphase structure of coarser-grained austenite and deformation-induced $\alpha^{\prime}$-martensite with mechanical twins was detected in the center of the cross-section. This microstructure indicates low forming temperatures during the manufacturing process of the semi-finished product (bar material), which leads to the occurrence of TWIP (TWinning Induced Plasticity) and TRIP (TRansformation Induced Plasticity) mechanisms. Apart from the center of the cross-section, an increasingly distorted, fine-grained austenitic microstructure is visible, indicating heat input from the surface during the manufacturing process of the bar material.

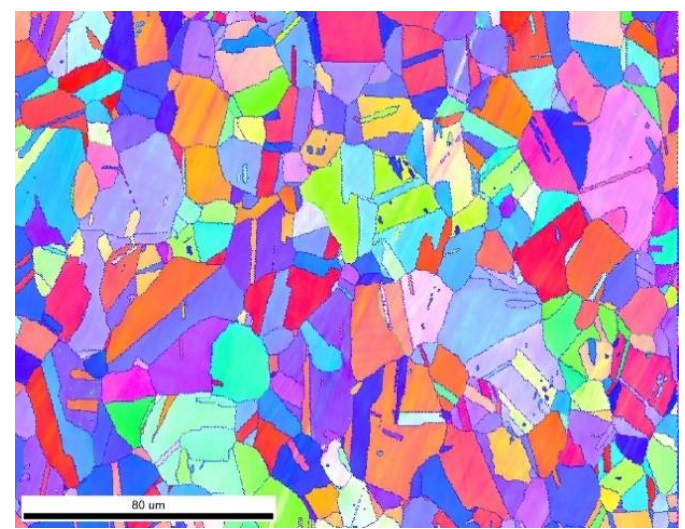

(a)

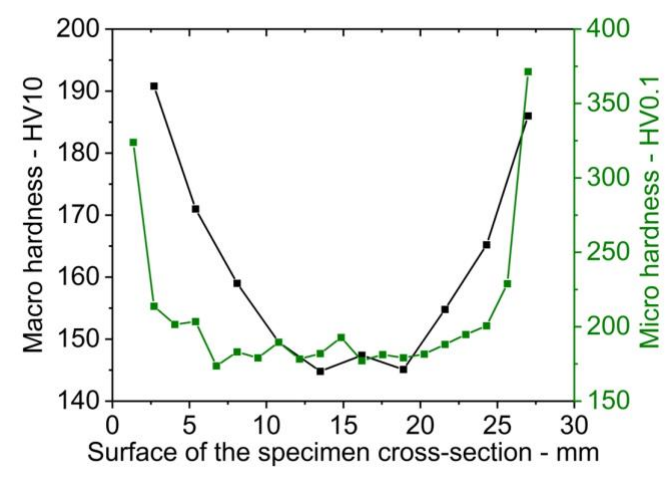

(b)

Figure 2. (a) EBSD-mapping of the cross-section center; (b) micro and macro hardness mapping of the cross-section of AISI 347 steel. 
The detection of the ferromagnetic portions by means of a Feritescope was able to confirm the previously described metallographic finding of $\alpha^{\prime}$-martensite. This ferromagnetic content increases from the cross-section edge to the center and reaches a maximum of 0.8 vol.- $\%$. $\delta^{\prime}$-ferrite was not detected in any of the metallographic investigations carried out. In addition, micro hardness measurements were performed with a Fisherscope HM 2000 and macro hardness measurements with a conventional hardness tester (Figure 2b). The Vickers micro hardness profile with a testing force of $0.98 \mathrm{~N}$ (HV0.1) shows a cup-shaped profile from approx. $340 \mathrm{HV} 0.1$ at the sample edge to approx. $180 \mathrm{HV} 0.1$ in the center. In comparison, macro hardness measurements were performed with a testing force of $98.07 \mathrm{~N}$ (HV10). In comparison to the micro hardness distribution, this curve shows an approximately narrower U-shaped progression. Here, the macro hardness is approx. $190 \mathrm{HV} 10$ in the edge area and approx. $145 \mathrm{HV} 10$ in the center. The gradient, which can be seen in both the micro and macro hardness measurements, can be related to the finer-grained microstructure in the edge region. The earlier hardness increase in the macro hardness measurements is attributed to the additional increase in $\alpha^{\prime}$-martensite formation due to the 100 times larger testing force.

In this project, specimens for two material conditions representing the initial condition and the aged condition are considered. Testing of the aged specimens served to qualify the NDT methods used to characterize the damage evolution during the tests. For aging, the specimens in the initial condition are set to an artificially defined aged condition by means of a practice-oriented thermo-mechanical loading. The parameters for the setting of the artificially aged condition were selected based on existing practice-relevant applications in nuclear technology [24,25]. These parameters for aging in air include a mechanical loading with a total strain amplitude of $0.3 \times 10^{-2}$, a strain rate of $4 \times 10^{-3} / \mathrm{s}$, and a thermal superposition with a temperature of $240{ }^{\circ} \mathrm{C}$, which represents the mean value of the temperature range from 150 to $325^{\circ} \mathrm{C}$.

To provide a data base required for the aging process with regard to the determination of the load cycles required to pre-damage, several fatigue specimens were loaded with the thermal and mechanical parameters up to a load drop $L$ of $25 \%$. Using statistical methods, the achieved lifetimes were evaluated, allowing load cycles (up to the failure criterion) to be calculated for different probabilities of survival. At a survival probability of $95 \%$, the obtained load cycle for $L 25 \%$ is 31,450 cycles. Here, the aged condition was defined by $0.5 \times L 25 \%$. Thus, the mechanical pre-damage results in 15,725 load cycles. The parameters examined experimentally and statistically ensured that the material AISI 347 is already transferred by the thermo-mechanical loading to a material condition that deviates significantly from the initial condition without already exhibiting macroscopically detectable damage characteristics.

\section{Results}

3.1. Comparison of Strain Increase Tests Performed under Laboratory Conditions in Air and in Distilled Water at Ambient Temperatures

Figure 3 shows results of the metastable austenitic AISI 347 steel in the initial condition obtained from two SITs performed (a) in air and (b) in distilled water with the slopes of the correlated total strain amplitude $\varepsilon_{a, t, c o r}$ (yellow), the stress amplitude $\sigma_{a}$ (green), the changes in tangential magnetic field strength $\Delta M_{\text {tang }}$ (blue), as well as the temperature $\Delta T$ (black) and the open circuit potential $E_{O C P}$ (red). 


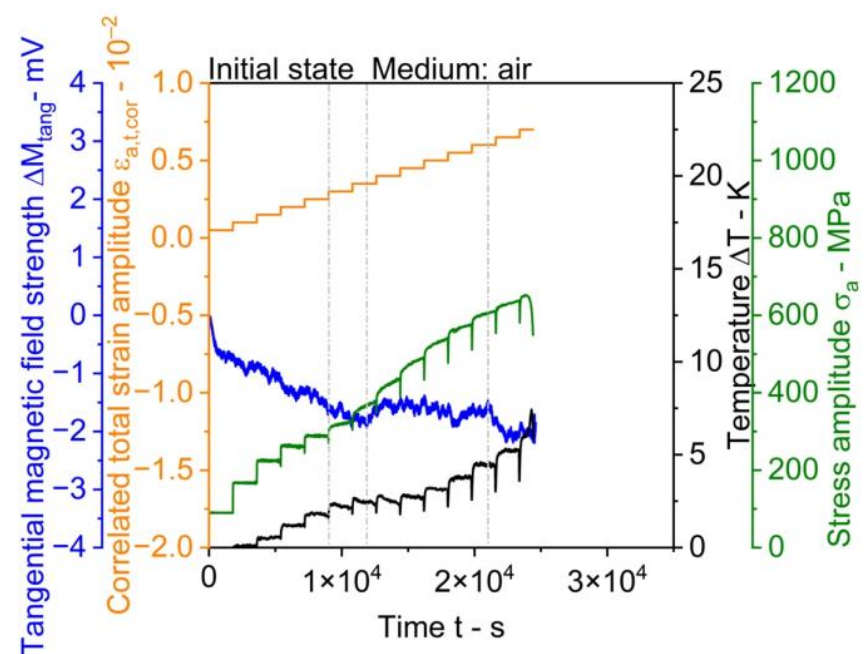

(a)

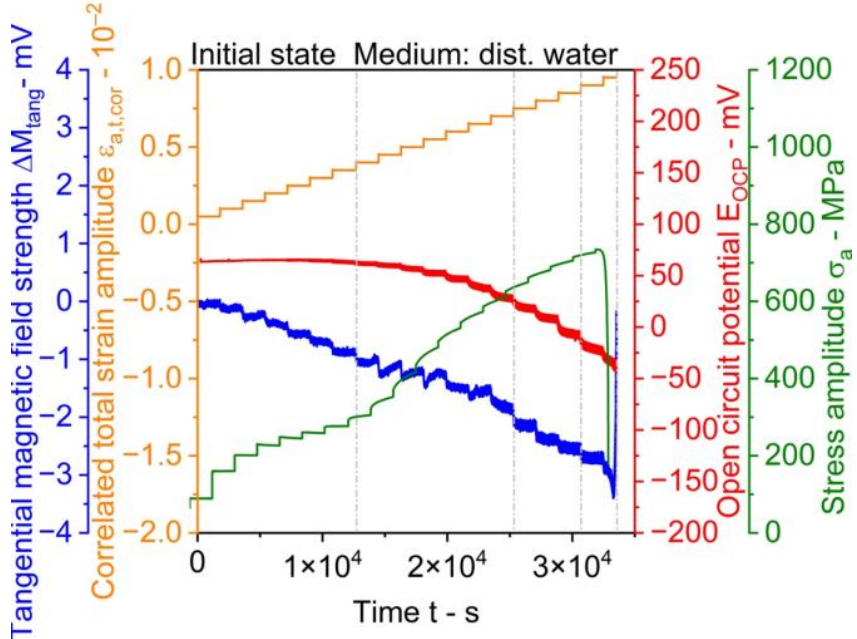

(b)

Figure 3. Results obtained from strain increase tests in (a) in air and (b) distilled water for specimens of the initial condition of AISI 347 steel.

The SITs performed within the scope of this research start with a total strain amplitude $\varepsilon_{a, t, \text { cor }}$ of $0.05 \times 10^{-2}$, and after a step length of $\Delta t=1800 \mathrm{~s}$ each, the total strain amplitude is increased by $\Delta \varepsilon_{a, t, c o r}=0.05 \times 10^{-2}$ until specimen failure. In Figure $3 a, \sigma_{a}$ also increases stepwise up to $\varepsilon_{a, t, c o r}=0.30 \times 10^{-2}$, whereupon from $\varepsilon_{a, t, c o r}=0.35 \times 10^{-2}$ onwards a hardening of the material takes place, which can be seen in a superimposed continuous increase of $\sigma_{a}$ within the step. Just before specimen failure, $\sigma_{a}$ decreases, indicating a drop-down in stiffness due to advanced macro crack propagation processes. $\Delta M_{\text {tang }}$ also exhibits a continuous decrease up to $\varepsilon_{a, t, c o r}=0.35 \times 10^{-2}$, which flattens thereafter and can be explained by the phase transformation from austenite to $\alpha^{\prime}$-martensite. Another change in the $\Delta M_{\text {tang }}$ progression is evident from $\varepsilon_{a, t, c o r}=0.60 \times 10^{-2}$, which is again related to macro crack propagation.

For the SIT performed in distilled water shown in Figure $3 b, \sigma_{a}$ also increases stepwise up to $\varepsilon_{a, t, c o r}=0.35 \times 10^{-2}$, after which there is also a superposition with continuous increases in $\sigma_{a}$ resulting from the strain amplitude-dependent hardening process. At $\varepsilon_{a, t, c o r}=0.95 \cdot 10^{-2}$ specimen failure occurs, indicated by a decrease in the $\Delta M_{\text {tang }}$ signal and a prior decrease in stiffness, which in turn is indicated by a decrease in $\sigma_{a} . \Delta M_{\text {tang }}$ decreases in a step-like manner as $\varepsilon_{a, t, c o r}$ increases until $\varepsilon_{a, t, c o r}=0.20 \times 10^{-2}$. The range of $0.40 \times 10^{-2}<\varepsilon_{a, t, c o r}<0.70 \times 10^{-2}$ indicates a deformation-induced phase transformation from austenite to $\alpha^{\prime}$-martensite, since there is a relative decrease within the steps.

\subsection{Comparison, Initial Condition and Aged}

SITs and CATs performed in distilled water were used to compare the initial condition with the aged condition of AISI 347 defined previously in Chapter 2. Figure 4a (same as Figure 3b) shows results from an SIT for a specimen under fatigue loading for AISI 347 in the initial condition showing the development over the time for the correlated total strain amplitude $\varepsilon_{a, t, c o r}$ (yellow), the stress amplitude $\sigma_{a}$ (green), the open-circuit potential $E_{O C P}$ (red) and the magnetic field strength $\Delta M_{\text {tang }}$ (blue), respectively, all up to specimen failure at $\varepsilon_{a, t, c o r}=0.95 \times 10^{-2}$. Here, $\sigma_{a}$ increases stepwise up to $\varepsilon_{a, t, c o r}=0.35 \times 10^{-2}$. At $\varepsilon_{a, t, c o r}=0.40 \times 10^{-2}$ onwards, a large increase in $\sigma_{a}$ can be seen until immediately before specimen failure. Afterward, there is a large decrease in stiffness at $\varepsilon_{a, t, c o r}=0.95 \times 10^{-2}$, which is accompanied by a decrease in $\sigma_{a}$. From $\varepsilon_{a, t, c o r}=0.40 \times 10^{-2}$ onwards, a stepwise decrease of the $E_{O C P}$ signal can be seen inverse to $\sigma_{a}$, which decreases more significantly from $\varepsilon_{a, t, c o r}=0.85 \times 10^{-2}$ onwards. $\Delta M_{\text {tang }}$ also decreases stepwise with increased $\varepsilon_{a, t, c o r}$, although the decrease intensifies from $\varepsilon_{a, t, c o r}=0.35 \times 10^{-2}$. In the range $0.40 \times 10^{-2}<\varepsilon_{a, t, c o r}<0.70 \times 10^{-2}$, a strong increase occurs within the load steps, which 
can probably be explained by the martensitic phase transformation. The specimen failure at $\varepsilon_{a, t, c o r}=0.95 \times 10^{-2}$ is reliable, indicated by a sudden decrease of the $\Delta M_{\text {tang }}$ signal.

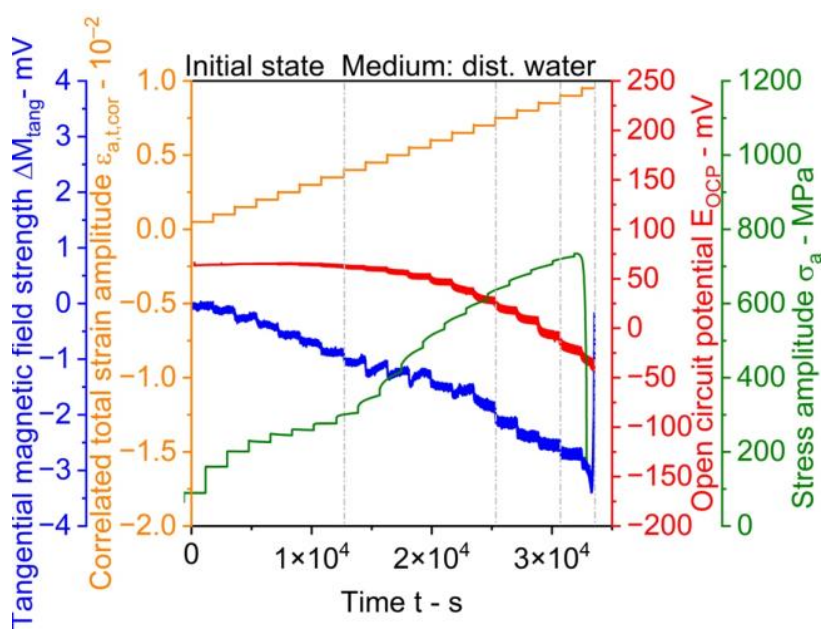

(a)

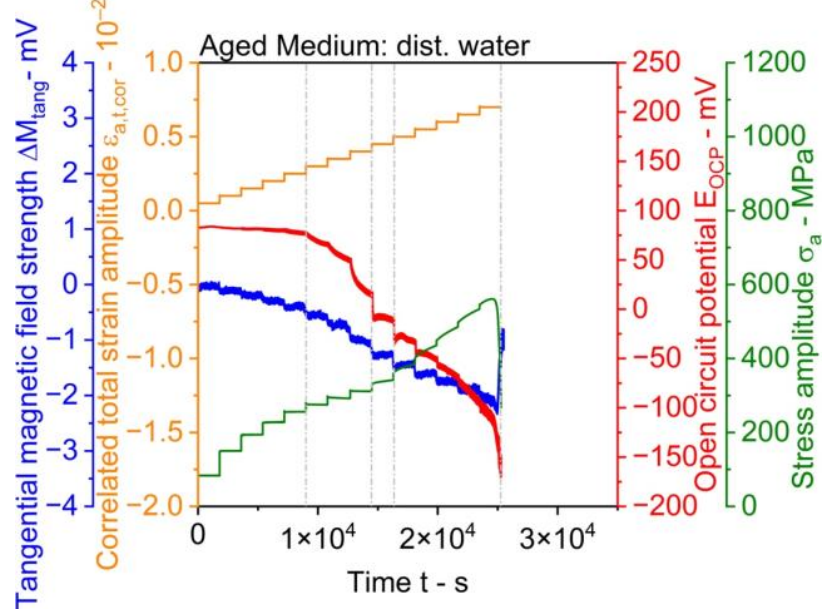

(b)

Figure 4. Strain increase tests in distilled water for (a) the initial condition and (b) the aged condition of AISI 347 steel.

Figure $4 \mathrm{~b}$ shows the SIT for the aged specimen. Comparatively, it can be observed that the aged specimen fails four load steps below the one in the initial condition (Figure 4a) at $\varepsilon_{a, t, c o r}=0.95 \times 10^{-2}$. The slopes of $\sigma_{a}, \Delta M_{\text {tang }}$ and $E_{O C P}$ are comparable to the initial condition up to a step of $\varepsilon_{a, t, c o r}=0.25 \times 10^{-2}$. Thereafter, the slopes are significantly different from the $E_{O C P}$. The $E_{O C P}$ signal of the aged specimen decreases considerably in the range $0.25 \times 10^{-2}<\varepsilon_{a, t, c o r} \leq 0.40 \times 10^{-2}$ within the steps. In the following three steps, the $E_{O C P}$ signal remains approx. constant in the step and again decreases continuously from $\varepsilon_{a, t, c o r}=0.60 \times 10^{-2}$ until specimen failure.

The increase of $\sigma_{a}$ in the first three load steps of the two SITs is due to a pure elastic behavior, which is reflected by the linear stress-strain relationship. From $\varepsilon_{a, t, c o r}=0.40 \times 10^{-2}$ for the specimen in the initial condition or from $\varepsilon_{a, t, c o r}=0.45 \times 10^{-2}$ for the aged specimen, the relative increase in $\sigma_{a}$ can be explained by cyclic hardening effects typical for that material under cyclic loading. The decrease in $\sigma_{a}$ in the last load step is due to progressive macro crack propagation in both the initial and aged conditions.

Prior the fatigue tests, the specimens were electrochemically stabilized in a load-free period at the beginning of the test, such that there were no active surfaces in the mediummaterial interface zone, as can be read from the constant $E_{O C P}$ slope. The subsequent stepwise decrease in relation to the change of $\varepsilon_{a, t, c o r}$ or $\sigma_{a}$ can be explained by activated surfaces exposed as a result of slip band movements and the associated intrusions and extrusions, which leads to a reduced $E_{O C P}$ signal in each step. By means of a decreasing strain hardening rate (visible from the $\sigma_{a}$ signal), $E_{O C P}$ continues to decrease in the step, which can be related to a stable and following unstable crack propagation processes with continuously new uncovered active surfaces. The constant range at the beginning of the experiment of the aged specimen is shorter and based on the aged condition of the material. The relatively significant changes at the step transition can probably be explained by pre-existing micro cracks in the material leading to anodic metal dissolution, whereupon the $E_{O C P}$ is shifted to a cathodic direction. The $E_{O C P}$ signal stabilizes after macro crack initiation until it transitions to the previously mentioned stable and then to the unstable crack propagation at $\varepsilon_{a, t, c o r}=0.55 \times 10^{-2}$ [26].

Figure 5 shows the results of two CATs in the low cycle fatigue (LCF) regime. The CAT for the initial condition was performed at $\varepsilon_{a, t, c o r}=1.46 \times 10^{-2}$ (Figure 5a) and for the defined aged condition at $\varepsilon_{a, t, c o r}=1.00 \times 10^{-2}$ (Figure $5 \mathrm{~b}$ ), respectively. Due to the strain hardening potential of the AISI 347 steel in the LCF regime, the total strain amplitudes lead to a constant increase in $\sigma_{a}$. The $E_{O C P}$ signal shows similar slopes for both conditions. In 
the case of the aged specimen, the $E_{O C P}$ signal starts at a higher level and shows a lower increase to the local maximum of the signal slope as it progresses. It increases in the first 25 load cycles, decreases steadily thereafter and becomes more pronounced briefly before specimen failure. $\Delta M_{\text {tang }}$ shows a predominantly inverse behavior compared to $\sigma_{a}$, with specimen failure indicated with a significant increase from at about $85 \%$ of the lifetime. The $\Delta M_{\text {tang }}$ slopes of both conditions can be compared very well with the individual slopes with corresponding total strain amplitudes in the SITs.

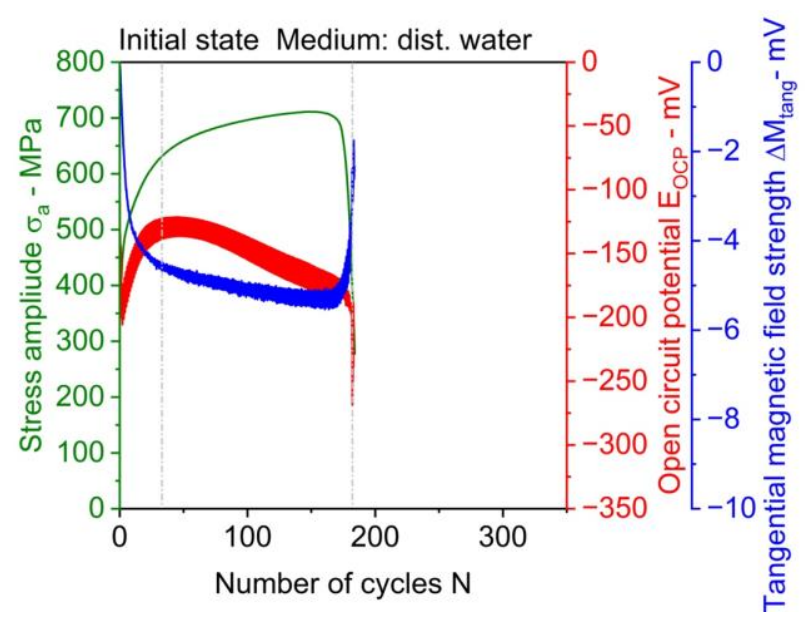

(a)

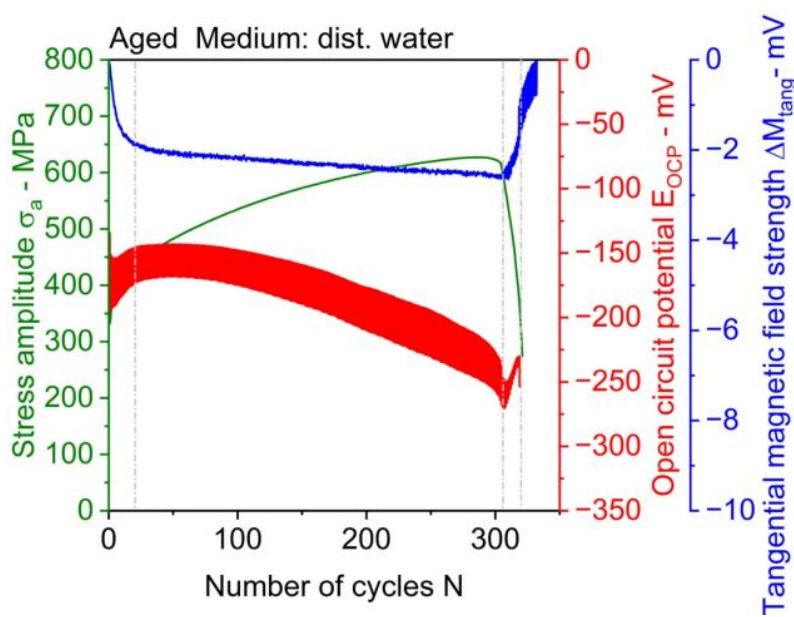

(b)

Figure 5. Constant amplitude tests in distilled water for (a) the initial condition and (b) the aged condition of AISI 347 steel.

\subsection{Constant Amplitude Tests Performed under Reactor Pressure Vessel Boiling Water Conditions}

To investigate the influence of application-relevant BWR conditions (c.f. Chapter 2), various fatigue tests were carried out in a respective environment. In this context, the course of the stress amplitude and the open-circuit potential were used to characterize the fatigue behavior. Figure 6 provides the results from two CATs performed under BWR conditions with total strain amplitudes of $0.3 \times 10^{-2}$ and $0.55 \times 10^{-2}$, respectively. Since with the CATs under BWR conditions, only a measurement of the specimen elongation at the specimen shoulders outside the autoclave is possible, a correlation between the elongation measured directly on the cylindrical gauge length of the specimen and the elongation determined at the specimen shoulders must be made on the basis of the fatigue tests in air as it was already described before. For this purpose, a strain measurement has been developed that makes it possible to perform tests after measuring the total strain amplitude at the gauge length of the specimen while observing symmetrical elongation amplitudes related to the measurement of two inductive displacement transducers at the specimen shoulders. After each loading cycle, the resulting strain amplitude is automatically evaluated online by the control system, and, if necessary, the elongation amplitude is increased or reduced in steps to subsequently obtain the desired total strain amplitude. By doing so, correlation curves were determined, which reflect the specimen elongations to be applied to the specimen shoulders in order to achieve constant strain amplitudes of the test length as a function of the number of cycles. These curves must be redetermined for all tests with different parameters via a best-fit correlation. 


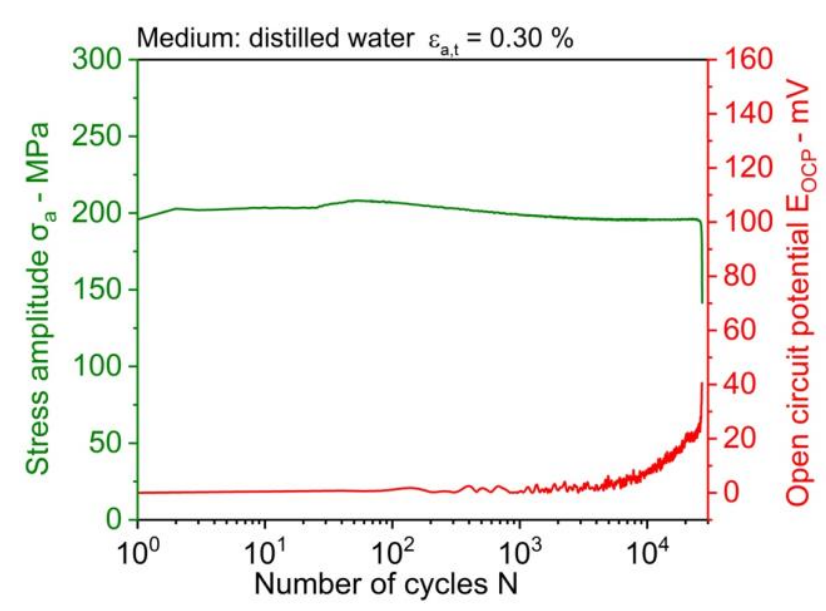

(a)

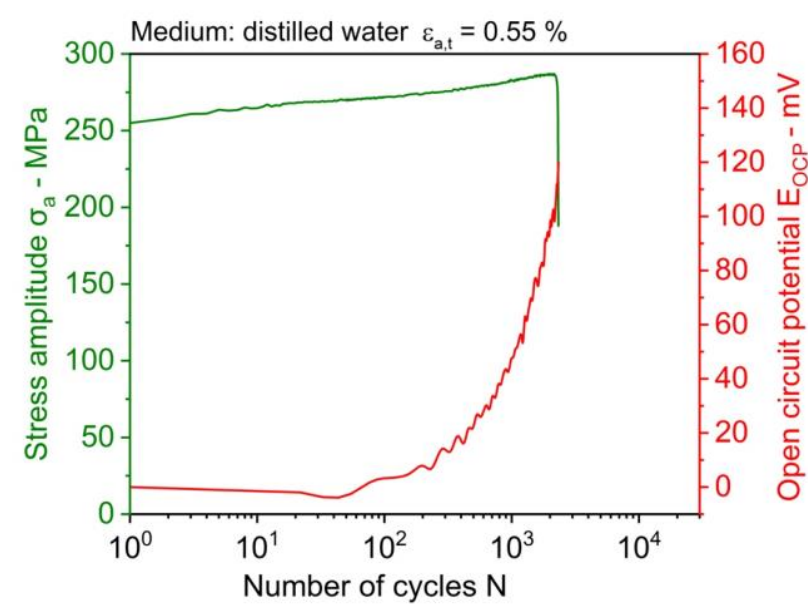

(b)

Figure 6. Total strain-controlled constant amplitude tests performed in BWR conditions with the courses of the stress amplitude and the open-circuit potential for (a) a total strain amplitude of $0.3 \times 10^{-2}$ and (b) a total strain amplitude of $0.55 \times 10^{-2}$ for the initial condition of AISI 347 steel.

Within the CAT with $\varepsilon_{a, t}=0.3 \times 10^{-2}$ (Figure 6a) it can be seen that the course of the stress amplitude remains almost constant from the beginning up to about 100 cycles and slightly decreases in the following, which is due to a cyclic softening of the material. Subsequently, saturation occurs, followed by a strong softening at specimen failure, indicated by a drop of the stress amplitude. With regard to the $E_{O C P}$ signal, this remains constant at a value of approx. 0 for the first 1000 cycles, after which there is a continuous increase until specimen failure. As it was already explained before, the signal changes in the open-circuit potential being dedicated to surface defects caused by the fatigue process.

Since the initiation of damage in the high cycle fatigue (HCF) regime almost certainly starts from the surface, the information obtained from this measurement technique is essential for the design of the components used in the field of nuclear energy. The exposure of new surfaces first leads to an increase in the corrosion current, with the open-circuit potential dropping locally. The subsequent re-passivation processes then lead to a respective increase in the open-circuit potential, which can be seen in Figure 6a.

In Figure 6b, the results from a CAT with a total strain amplitude of $\varepsilon_{a, t}=0.55 \times$ $10^{-2}$ are shown. Due to the higher total strain amplitude when compared to the results in Figure 6a, cyclic deformation behavior changes to a continuous cyclic hardening behavior over the entire lifetime indicated by a continuous increase in the stress amplitude. The $E_{O C P}$ signal also shows a behavior comparable to the CAT with the lower total strain amplitude, changing by about $55 \%$ from its initial value to specimen failure.

\subsection{StrainLife}

StrainLife is a STEP for the fast and cost-effective evaluation of S-N curves, which is considered here to be adapted and validated to nuclear engineering applications. The value of this method is, as mentioned before that only one SIT and two total strain-controlled CATs are required for the calculation of a complete total strain S-N curve. The input variables for the StrainLife method include the measurements of $\sigma_{a}, \varepsilon_{a, p}, \Delta T, \Delta R, E_{O C P}$ and $\Delta M_{\text {tang, }}$, respectively, with their development over the fatigue life to be considered as an additional source of information, as shown for the different experimental results presented before. In the following, the procedure is described for the calculation based on electrical resistance values. 
Equation (1) is a relationship by Morrow [27], which is commonly used to describe the stress amplitude (load variable) and to be a function of plastic strain amplitude (material response).

$$
\sigma_{a}=K^{\prime} \times\left(\varepsilon_{a, p}\right)^{n^{\prime}}
$$

By using the load quantity $L$ and the material response $M$, Equation (1) can now be described as follows.

$$
M=K^{\prime}{ }_{M} \times(L)^{n_{M^{\prime}}}
$$

Here, the coefficient $K_{M}^{\prime}$ and the exponent $n_{M^{\prime}}$ are additionally marked with the index $M$ to express that this formula is used for a quantity other than the mechanical plastic strain amplitude. Those relationships provide the basis to determine S-N curves may be derived from an SIT, where the load quantity could be considered to be a total strain amplitude $\varepsilon_{a, t}$ and the material response electrical resistance $\Delta R$ written then as

$$
\Delta R=K_{\Delta R}^{\prime} \times\left(\varepsilon_{a, t}\right)^{n} \Delta R^{\prime}
$$

The next step is to calculate the average values of the change in electrical resistance of each load level of the SIT and then plot the total strain amplitude as a function of these values (see Figure 7a). In addition, two CATs are performed, which are also added to the same plot. In the respective example, the change in electrical resistance at the same total strain amplitude in the LIT and CAT may not be identical, which can be attributed to a difference in load-time history between LIT and CAT, resulting in different material conditions with respect to damage accumulated up to the respective point, as well as cyclic strain hardening (Figure $7 b$ ). To correct this a ratio, $Q$, between the total strain amplitude of the CAT and the SIT is calculated according to Equation (4).

$$
Q\left(\varepsilon_{a, t, 1 / 2}\right)=\frac{\Delta R_{1 / 2}(\mathrm{CAT})}{\Delta R_{1 / 2}(\mathrm{SIT})}
$$

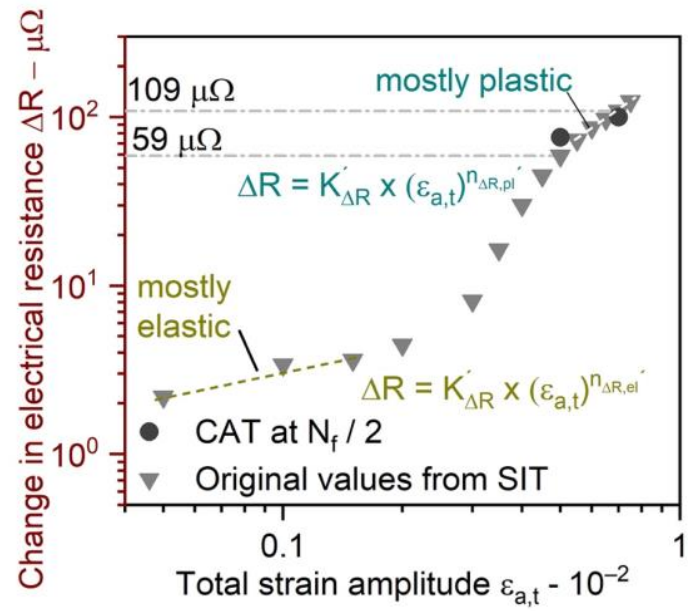

(a)

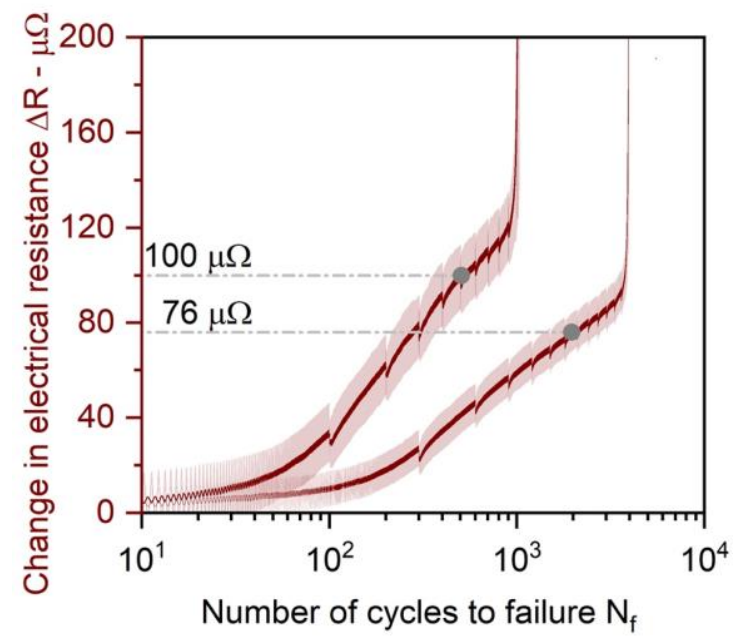

(b)

Figure 7. (a) Morrow curve for the SIT and the values of the change in electrical resistance $\Delta R$ at $N_{f} / 2$ of the two CATs in distilled water for the initial condition and (b) the CATs in distilled water for the initial condition of AISI 347 steel.

Using the calculated corrective values, $Q$, for both total strain amplitude levels applied in the CATs, a fitting curve for further extrapolation of the data is calculated, where an exponential fit has been chosen. By using this relationship, the stress-strain behavior of the SIT is transferred to the stress-strain behavior for strain-controlled CATs (see Figure 8). 


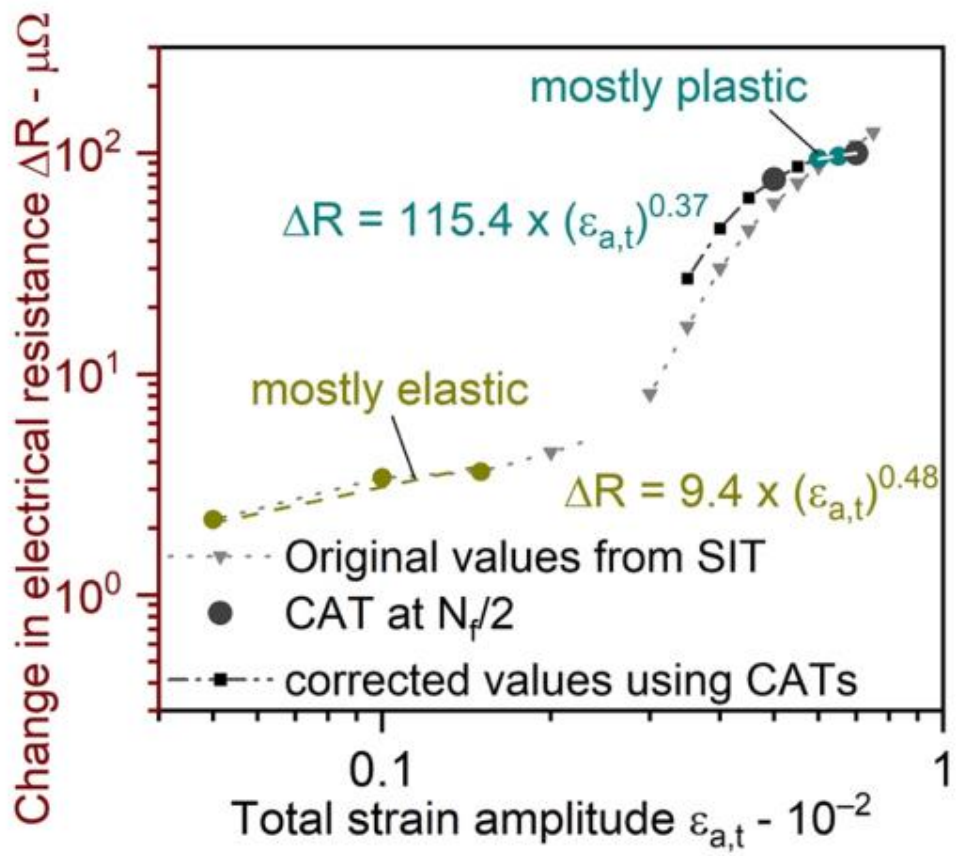

Figure 8. Calculated Morrow curve with identified predominantly elastic and plastic regions of strain increase and constant amplitude tests in distilled water for the initial condition of AISI 347 steel.

If electrical resistance is considered to be the relevant material response $M$, then this may need to be differentiated between a predominantly elastic and predominantly plastic strain region when plotting the relationship between the material response $M$ and the load variable $L$. Therefore, coefficient $K_{\Delta R}^{\prime}$ and exponent $n_{\Delta R^{\prime}}$ have to be differentiated in accordance with the two regions. Equation (3) turns up in two versions, including the exponents $n_{\Delta R, e l^{\prime}}$ and $n_{\Delta R, p l^{\prime}}$, respectively (see Figure 8). Using $n_{\Delta R, e l^{\prime}}$ and $n_{\Delta R, p l^{\prime}}$, the fatigue strength exponent $b$ and fatigue ductility exponent $c$ can be calculated using Equations (5) and (6), respectively [27].

$$
\begin{aligned}
& b=\frac{-n_{\Delta R, e l}{ }^{\prime}}{5 \times n_{\Delta R, e l^{\prime}}+1} . \\
& c=\frac{-1}{5 \times n_{\Delta R, p l^{\prime}}+1}
\end{aligned}
$$

The total strain amplitude contains an elastic portion $\varepsilon_{a, e l}$ and a plastic portion $\varepsilon_{a, p l}$ being additive, as it is shown in Equation (7).

$$
\varepsilon_{a, t}=\varepsilon_{a, e l}+\varepsilon_{a, p l}
$$

In the case of mechanical stress-strain measurements, the elastic and plastic portion vs. the number of cycles to failure can be described mathematically equivalent to Basquin (Equation (8)) [28] and Mansion-Coffin equations (Equation (9)) [29], respectively. An example of such a separation into an elastic and a plastic portion is exemplarily shown in Figure 9a using the strain measurement as an example.

$$
\begin{aligned}
& \varepsilon_{a, e l}=B \times\left(2 N_{f}\right)^{b} \rightarrow B=\frac{\varepsilon_{a, e l}}{\left(2 N_{f}\right)^{b}} \\
& \varepsilon_{a, p l}=C \times\left(2 N_{f}\right)^{c} \rightarrow C=\frac{\varepsilon_{a, p l}}{\left(2 N_{f}\right)^{c}}
\end{aligned}
$$




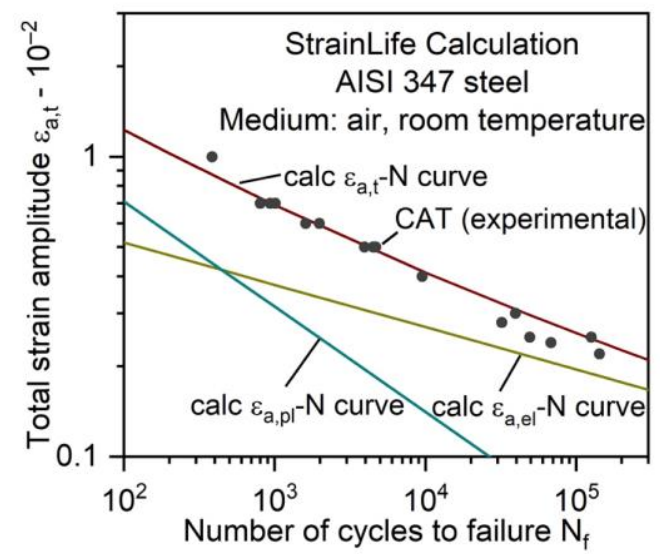

(a)

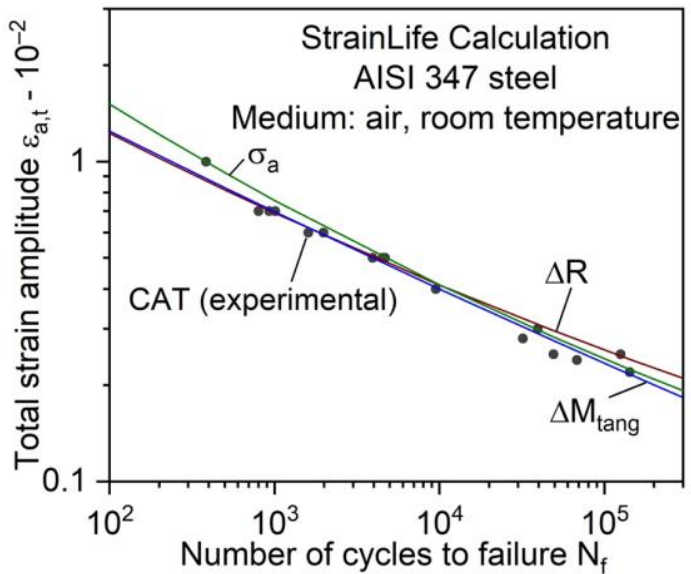

(b)

Figure 9. (a) Slopes of the Basquin and Mansion-Coffin relationships, as well as the comparison of conventional determined fatigue data with the StrainLife curve calculated based on stress-strain data and (b) comparison of conventional determined fatigue data with the StrainLife curves calculated based on stress-strain, electrical resistance and magnetic field strength data for the initial condition of AISI 347 steel.

If the slopes determined according to Equations (5) and (6) are entered into Equations (7)-(9), Equation (10) is obtained. Since at least always two CATs are performed, the coefficients $B$ and $C$ can be determined via Equation (10).

$$
\varepsilon_{a, t}=B \times\left(2 N_{f 1 / 2}\right)^{\frac{-n}{5 \times n} \Delta R, e l^{\prime} l^{\prime}}+C \times\left(2 N_{f 1 / 2}\right)^{\frac{-1}{5 \times n} \Delta R, p l^{\prime+1}}
$$

Figure 9a gives the result of the StrainLife calculation based on stress-strain measurements. Aside from the calculated S-N curve, the curves for Basquin (elastic portion) and the Manson-Coffin (plastic portion) relationships are also given. Figure $9 \mathrm{~b}$ additionally shows the calculated StrainLife curves based on the changes in electrical resistance and the tangential magnetic field strength [30].

\subsection{Uncertainties of Crack Position and Progression on Total Strain Controlled Fatigue Results}

Fatigue life is defined by a damage criterion considered, which is in many traditional cases, is the complete fracture of the specimen. However, this is just one damage mechanism (and the last) that occurs during the fatigue life of a material. In many cases, the damage criterion is considered to be crack initiation only. This is to give clear recognition of the description of linear and non-linear fracture mechanics approaches being a mechanism different when compared to the degradation processes appearing before crack initiation. Care has to be taken when the crack propagation phase is included in the fatigue life evaluation, specifically when strain is the controlling mode. In that case, the number of cycles can go up to infinity when a crack opening displacement is erroneously taken as a basis to determine a specimen's strain.

An alternative to crack initiation is to measure load drop when the fatigue test is performed under strain control. This is well feasible with unnotched specimens when generating materials fatigue data. However, the question arises, which crack size can be associated with a defined load drop criterion.

For the description and evaluation of the incident of crack initiation, the transition between a fatigue analysis from the uncracked to the cracked structure where fracture mechanics-based evaluations in the LCF regime of the components considered are essential. Based on the results of the fatigue tests presented here, the specimens were analyzed with respect to the location of crack initiation and the assumption to be made [31]. The changes in the stress amplitudes of the total strain-controlled fatigue tests (e.g., Figure 4a) are related to crack geometries and crack sizes in order to develop an appropriate correlation. 
For this purpose, four possible crack geometry configurations of the incipient cracks in the cross-sectional area of the specimen are considered. These possible incipient cracks are a circular crack (fisheye), a full circumferential crack, a chord crack and a lens crack, all schematically shown in Figure 10. The circular crack may initiate at an inclusion, as it could be expected for ideal geometrically unnotched specimens [32]. In comparison, the development of a chord or lens crack, e.g., due to an arbitrary unwanted condition (e.g., blade of a strain gauge transducer), may occur in non-ideal geometrically unnotched specimens. The full circumferential crack is predominantly to be expected on notched specimens.
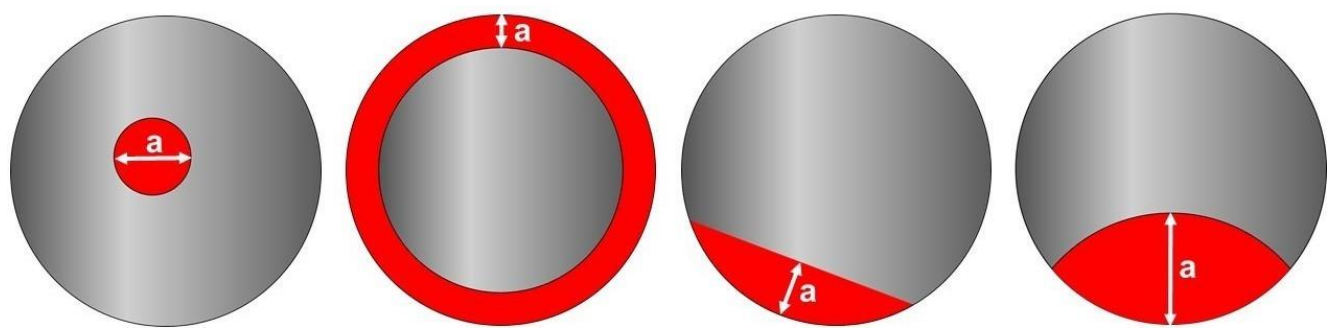

Figure 10. Possible crack configurations on fatigued specimens: Circular, full circumferential, chord and lens crack.

The crack area $A$ is different for each crack initiation configuration and depends on the crack depth a. A can be calculated according to Equations (11)-(14), which is also visualized in Figure 11. For this case, the radius of the cross-sectional area of the unnotched fatigue specimens is assumed to be $r=5 \mathrm{~mm}$. Figure 11 also contains the area fractions with associated crack depths of individual fatigue specimens with a load drop of $25 \%$, which were tested with a strain amplitude of $0.3 \times 10^{-2}$. The individual fractographs are shown in more detail in Figure 12. The fractographs show that the lens crack is a possible idealized crack shape. In addition, the location of the extensometer clip is marked with a green dot in the fractographs. The respective crack areas depend on the stress level and the present number of cycles until specimen failure has occurred.

$$
\begin{gathered}
A_{\text {Circular }}=\pi \times a^{2} \\
A_{\text {full circumferential }}=\pi \times\left[r^{2}-\left(r-a^{2}\right)\right] \\
A_{\text {Chord }}=\frac{\pi}{2} \times r^{2}-(r-a) \times \sqrt{a \times(2 \times r-a)}-r^{2} \times \arctan \frac{r-a}{\sqrt{a \times(2 \times r-a)}} \\
A_{\text {lens }}=2 \times \frac{\pi}{2} \times r^{2}-2 \times\left(r-\frac{a}{2}\right) \times \sqrt{a \times\left(r-\frac{a}{2}\right)}-2 \times r^{2} \times \arctan \frac{r-\frac{a}{2}}{\sqrt{a \times\left(r-\frac{a}{2}\right)}}
\end{gathered}
$$

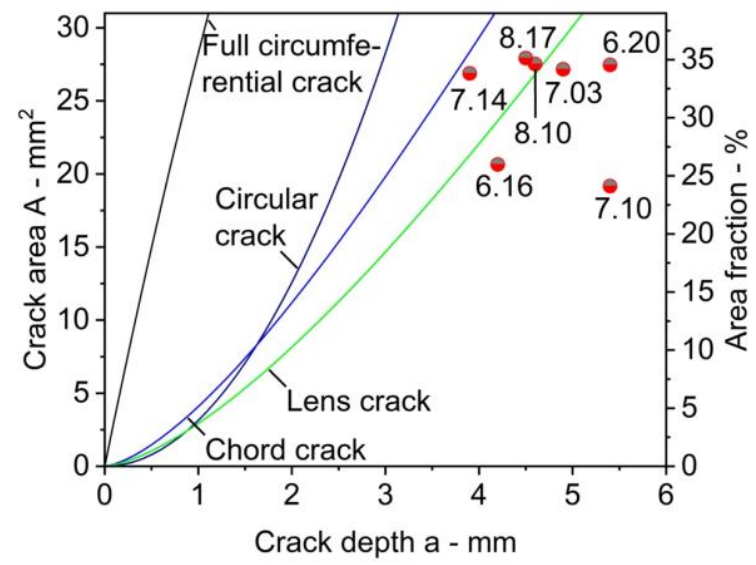

Figure 11. Crack area and area fraction vs. crack depth for possible crack configurations (cf. Figure 10). 


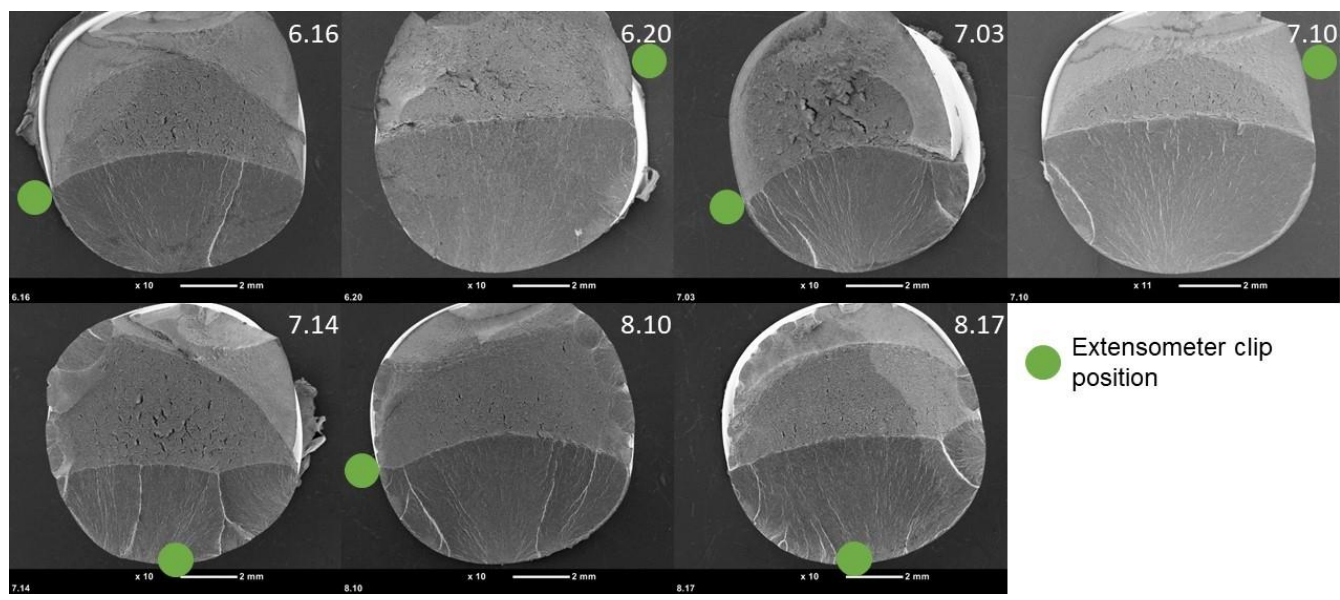

Figure 12. Specimens' fracture surfaces with extensometer clip position indicated by a green dot and specimen number codes given.

The numerical analysis tool PROST uses the structure of a solid cylinder for the minimum cross-section of an unnotched specimen with a chord crack so that the crack propagation, as well as the stability of incipient cracks, can be compared with the previously determined measurement results. In the case of pure tensile load (cf. Equation (15)), an analytical approach for stress intensity factors can be used according to [9], which is based on the British Standard 7910. This is valid for relative crack depths $(a / 2 \times r)$ in the range of $6.25 \%$ to $62.5 \%$.

$$
\begin{aligned}
K=\sqrt{\pi \times a} \times \sigma & \times\left[0.926-1.771 \times\left(\frac{a}{2 \times r}\right)^{1}+26.421 \times\left(\frac{a}{2 \times r}\right)^{2}-78.481 \times\left(\frac{a}{2 \times r}\right)^{3}\right. \\
& \left.+87.911 \times\left(\frac{a}{2 \times r}\right)^{4}\right]
\end{aligned}
$$

A limiting load criterion can be determined from the ratio of the ligament area to the cross-sectional area of the undamaged specimen with the crack area $A_{\text {Chord }}$. The fracture mechanics determination of the crack propagation is carried out by the fatigue crack propagation law according to [33] for austenitic steels (cf. Equation (16)).

$$
\frac{d a}{d n}=3.43 \times 10^{-12} \times S(R) \times\left(\Delta K^{3.3}+C\left(c_{O_{2}}\right) \times \sqrt{S(R) \times T_{R}} \times(\Delta K)^{1.65}\right.
$$

Here $\Delta K$ is given in (MPa $\sqrt{ } \mathrm{m})$ and crack propagation in $(\mathrm{m} / \mathrm{cycle}) . T_{R}$ is the time of load increase in (s), $\mathrm{CO}_{2}$ is the dissolved oxygen concentration in (ppm). $C$ is a function dependent on the dissolved oxygen concentration. The function $S(R)$, which contains the load ratio $R$, is defined by Equation (17).

$$
S(R)=\left\{\begin{array}{cc}
1 & R<0 \\
1+1.8 \times R & 0<R<0.8 \\
-43.35+57.97 \times R & R>0.8
\end{array}\right.
$$

The description of the crack propagation according to [28] is only valid for load ratios $R \geq 0$. Investigations on austenitic steels have shown that the application of the correlation for $R=0$ is also possible for negative load ratios in fatigue tests in air as an ambient medium [34]. Therefore, the function $S(R)$ for the crack-closure load was extended to include extrapolation to negative $R$ values. The first term of the crack propagation law (cf. Equation (16)) describes the crack propagation in an air environment, while the second describes the medium component. The crack propagation law in an air environment and $R=-1$ is shown in Figure 13 (blue curve, left axis). The fatigue crack propagation law becomes a straight line in a double logarithmic plot. In the area shaded in blue, the load peak has a linear-elastic stress intensity factor $K_{\max }>K_{I C}$. In this area, even linear-elastic crack initiation or even specimen failure can be expected (in the elastic-plastic calculation, 
initiation can be expected earlier). In order for this behavior to be set in relation to the crack load, $\Delta K$ is also plotted as a function of crack depth for different nominal strain amplitudes (green lines). Thus, for a given crack depth $a$, the corresponding $\Delta K$ can be read from the desired load amplitude. Starting from the abscissa value, the crack propagation rate can be determined. This procedure is exemplified in Figure 13 with brown arrows. The process shown in Figure 13 is only a rough approximation since the crack propagation law may not lie exactly within the range considered.

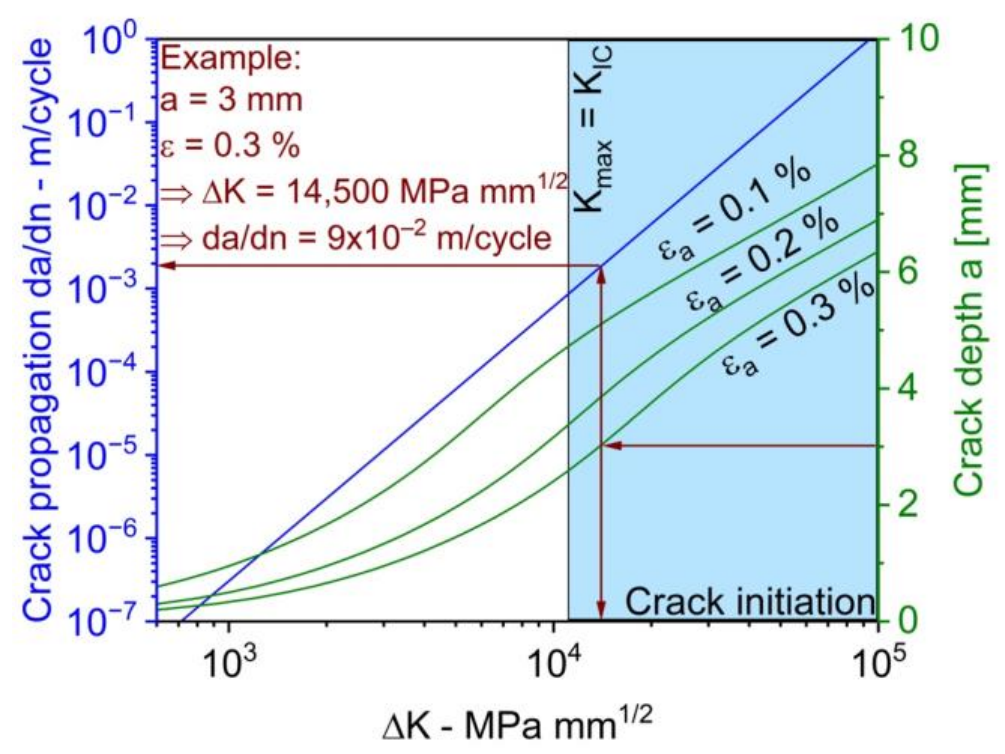

Figure 13. PROST diagram for determining the crack propagation rate, based on the analytical method according to [33] for air and $R=-1$.

Figure 14 shows the function of load drops for a constant strain amplitude of $0.3 \times 10^{-2}$. The diagram also contains the crack sizes determined during the test, which are further used as input variables in the calculation, e.g., using the PROST analysis tool. Horizontal dashed lines indicate the geometrical estimation of the crack depth $a$. The bars (slightly shifted to avoid overlapping) indicate the possible ranges of possible crack lengths depending on the extensometer clip position. The calculation results are focused on a load drop of $25 \%$.

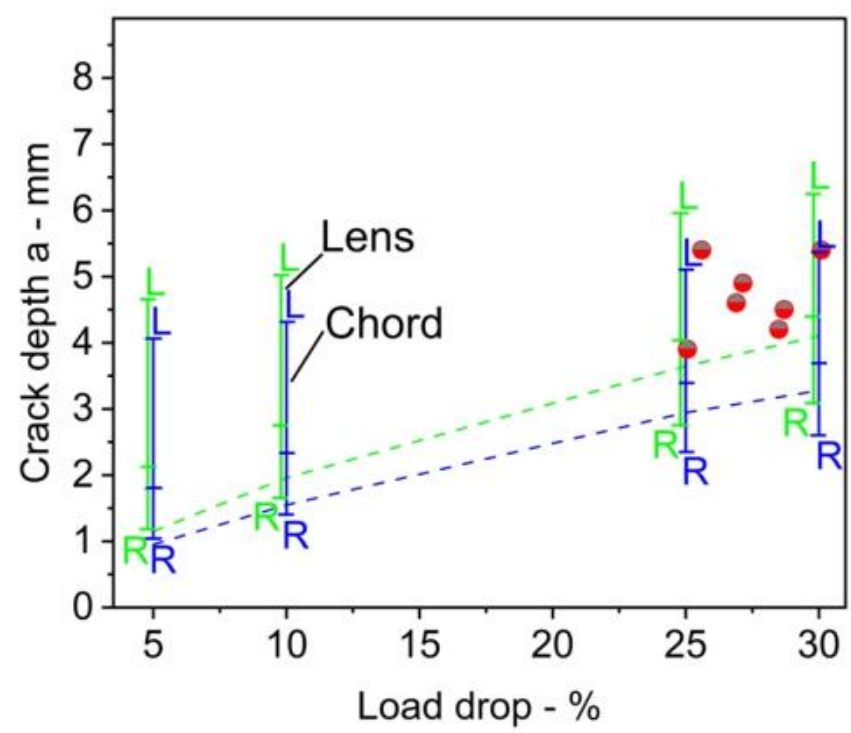

Figure 14. Calculated incipient depth as a function of load drop. 
For total strain amplitudes larger than $1 \times 10^{-2}$, it should be noted that the reliability of the present calculations is limited since the Chaboche parameters were adjusted for relatively small total strain amplitudes. Further investigations and results of this work are described in more detail in [31].

From the investigation of crack sizes associated with the fatigue life achieved, an estimation can be proposed that gives a probability of a certain crack size at the defined load drop. The relation is based on the range spanned by two idealized crack shapes related to the experimental findings. The following equation approximates the full span of values for possible crack sizes for an assumed load drop $d_{L}$ (relative value), based on data of CATs with a total strain amplitude of $0.3 \times 10^{-2}$ (Figure 14).

$$
a \in\left[4.7 \mathrm{~mm} \times \sqrt{d_{L}} \times 4.4 \mathrm{~mm}+6.4 \times d_{L}\right]
$$

These values of a minimum and maximum envelope of the crack depths measured in the CATs are shown in Figure 15. Considering the possibilities, the experimentally observed cracks are within the range predicted by the numerical simulation, which allows possible corrections in terms of the scatter of fatigue life data with respect to a defined crack initiation criterion to be made.

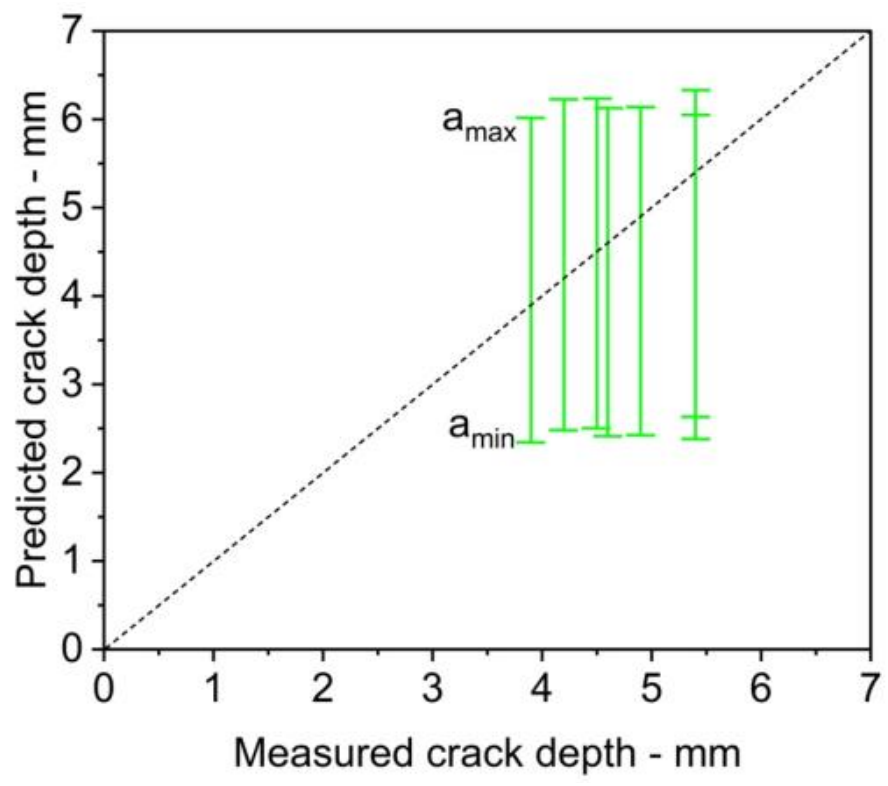

Figure 15. Comparison of predicted crack depth ranges according to Equation (18) for all measured cracks (fatigue tests with a total strain amplitude of $0.3 \times 10^{-2}$ ) is shown in Figure 11 .

\section{Conclusions}

This paper underlines that parameters determined from non-destructive and electrochemical testing can be used as an alternative or even as an improvement to the traditional parameters of load, stress, deformation and strain to determine the fatigue life of metallic materials and components. This has been demonstrated for the metastable AISI 347 (1.4550) steel in an initial and aged condition with a clear view on nuclear engineering. Changes in temperature, electric resistance, tangential magnetic field strength or in open circuit potential are among those NDT-based techniques from where measurements can be derived, which show adequate if not even better performance when compared to mechanical stressstrain hysteresis, being one of the state-of-the-art measurement techniques. Parameters derived from those NDT techniques can possibly be easier accessed when compared to plastic strain measurements, and they may possibly be more sensitive when looking at specific cases, where this article is only providing a limited example and can still not claim to demonstrate the full potential of such an approach lying ahead. 
It has been shown for media conditions, such as distilled water, as well as reactor pressure vessel boiling water (BWR), that NDT measurements still hold, and that the NDTbased parameters can even be derived appropriately under such environmental conditions. Since the NDT-based parameters derived can be used to determine S-N curves, even in the context of short-time procedures where only a fraction of effort is required to generate an S-N curve when compared to state-of-the-art, a completely new field of generating S-N data is opened.

Considering components in nuclear engineering often being exposed to strain-controlled loading conditions, at least in the locations where fatigue damage becomes critical, the StrainLife method has been specifically developed and explained based on electrical resistance measurements. It is based on the fact that materials' fatigue data for the stage until crack initiation can be used and transferred to evaluate and assess the fatigue life of components. In that context, the question of what damage-or better, degradation-is, is still not sufficiently solved. However, there is hope for improvement. The current view is still that cracks, and specifically their size, are a characteristic of damage and a structure's vulnerability. Numerical simulation has proven that an understanding between loading conditions and degradation criteria (damage) within a material and a structure can be well established and can help to further improve the reliability of materials' fatigue data generated, specifically with respect to short-time procedures, such as shown with the assessment of crack initiation uncertainties in the case of StrainLife here.

\section{Outlook}

StrainLife is on the way to becoming an integral part of structural mechanical analysis codes in nuclear engineering, where the tool of PROST, which has been referenced in this paper, is an example. Implementing such methods in tools for integrity assessments does not only ease the provision and application of S-N data within the code but can also help to guide inspection processes of components in the future in a way that the code may be able to predict which parameter should be measured best at which location and how accumulated damage may be assessed best at a macroscopically still-uncracked stage. Evidence for such approaches is currently being tested as part of the "MiBaLeb"-project, of which the second phase is due to be run into the year 2023.

Author Contributions: Conceptualization, J.S. and P.S.; methodology, R.A. and P.S.; software K.H. and J.S.; validation, R.A., L.L. and T.S.; formal analysis, K.H. and P.S.; investigation, T.B., R.A., T.S., K.D. and L.L.; resources, F.W. and P.S.; data curation, T.B., R.A., K.D. and L.L.; writing-original draft preparation, T.B. and P.S.; writing-review and editing, C.B., F.W. and K.H.; visualization, T.B.; supervision, J.S., F.W., C.B., S.W. and P.S.; project administration, C.B., S.W., J.S., F.W. and P.S.; funding acquisition, C.B., S.W., J.S., F.W. and P.S. All authors have read and agreed to the published version of the manuscript.

Funding: This research was funded by the Federal Ministry of Economic and Energy (BMWi) within the framework of the joint project "Microstructure-based determination of the maximum service life for corrosion fatigue loaded materials and components of nuclear technology", part I, funded grant number 1501528A, 1501528B, 1501528C, RS1545 and part II, funded grant number 1501610A, 1501610B, 1501610C, 1501610D and RS1594E, respectively.

Institutional Review Board Statement: Not applicable.

Informed Consent Statement: Not applicable.

Data Availability Statement: The data presented in this study are available on request from the corresponding author.

Acknowledgments: The authors from WWHK thank the University of Applied Sciences Kaiserslautern for financial support under the "Budget for Research and Innovation" funding program for the procurement of research infrastructure used in this project (digital microscope and servohydraulic fatigue testing system). The authors would also like to thank Shimadzu Germany/Europe for their support in technical equipment provision. The authors from TU Dortmund University thank the 
German Research Foundation for their financial support within the Major Research Instrumentation Program for "servohydraulic fatigue testing system 250 kN" (INST 212/325-1 FUGG).

Conflicts of Interest: The authors declare no conflict of interest.

\section{References}

1. Kalwa, G.; Haarman, K. Das Rohr im Modernen Kraftwerksbau; Stahl und Eisen, Band 102, Heft 17; A. Bagel Verlag: Köln, Germany, 1982; pp. 53-56.

2. Rudolph, J.; Götz, A.; Hilpert, R. Regelwerkskonforme Bestimmung von Erschöpfungsgraden bei allgemeinen elasto-plastischen Finite-Elemente-Analysen. Teil 1 und 2. Technische Sicherheit Bd. 2 Nr. 7/8 und 9, Germany. 2012, pp. 60-64. Available online: https: / docplayer.org/76695351-Regelwerkskonforme-bestimmung-von-erschoepfungsgraden-bei-allgemeinen-elastoplastischen-finite-elemente-analysen.html (accessed on 23 November 2021).

3. Heckmann, K.H.; Grebner, J. Sievers: Weiterentwicklung Probabilistischer Analysemethoden zur Lebensdauerbestimmung von Rohrleitungen und Behältern, GRS-A-3709. July 2013. Available online: https:/ / www.grs.de/sites/default/files /pdf/GRS-A-37 09.pdf (accessed on 23 November 2021).

4. KTA 3201.2: Komponenten des Primärkreises von Leichtwasserreaktoren Teil 2: Auslegung, Konstruktion und Berechnung, Sicherheitstechnische Regel des Kerntechnischen Ausschusses (KTA), Fassung 2017-11. 2013. Available online: http://www.ktags.de/d/regeln/3200/3201_2_r_2017_11.pdf (accessed on 23 November 2021).

5. Heckmann, K.; Ma, K.; Sievers, J. Probabilistic aspects on break preclusion assessment in nuclear piping. In Proceedings of the Contribution to the 41st MPA-Seminar, Stuttgart, Germany, 5-6 October 2015.

6. Wang, Y.; Sievers, J. Probabilistic analysis of 3d mixed mode fatigue crack propagation in a feed water nozzle under cyclic thermal loading. In Proceedings of the 18th European Conference on Fracture, Dresden, Germany, 30 August-3 September 2010.

7. Palmgren, A. Die Lebensdauer von Kugellagern, Zeitschrift des Vereines Deutscher Ingenieure. Sci. Res. 1924, 68, 339-341.

8. Miner, M.A. Cumulative damage in fatigue. J. Appl. Mech. 1945, 12, A159-A164. [CrossRef]

9. Erve, M. Die Bedeutung der Werkstofftechnik beim Lebensdauermanagement (Plant Life Management) für nukleare Anlagen. In Proceedings of the 23rd MPA-Seminar, Stuttgart, Germany, 1-2 October 1997.

10. Acosta, R.; Wu, H.; Venkat, R.S.; Weber, F.; Tenkamp, J.; Walther, F.; Starke, P. SteBLife, a new approach for the accelerated generation of Mmetallic materials' fatigue data. Metals 2020, 10, 798. [CrossRef]

11. Germann, H.; Starke, P.; Eifler, D. Resistivity Based Evaluation of the Fatigue Behaviour of Cast Irons. Suppl. Proc. 2011, 43, 675-682. [CrossRef]

12. Starke, P.; Klein, M.; Eifler, D. Resistivity-A characteristic fingerprint of fatigue induced changes in the microstructure of metallic materials. Procedia Eng. 2011, 10, 698-703. [CrossRef]

13. Starke, P.; Walther, F.; Eifler, D. "PHYBAL" a short-time procedure for a reliable fatigue life calculation, Advanced Engineering. Materials 2010, 12, 276-282.

14. Starke, P.; Eifler, D.; Walther, F. Model-based correlation between electrical resistance and the dislocation structure of fatigued ICE R7 wheel steel. Mater. Test. 2018, 60, 669-676. [CrossRef]

15. Walther, F. Microstructure-Oriented Fatigue Assessment of Construction Materials and Joints Using Short-Time Load Increase Procedure. Mater. Test. 2014, 56, 519-527. [CrossRef]

16. Schmiedt-Kalenborn, A. Mikrostruturbasierte Charakterisierung des Ermüdungs- und Korrosionsermüdungsverhaltes von Lötverbindungen des Austenits X2CrNi18-9 mit Nickel- und Goldbasislot. In Werkstofftechnische Berichte; Springer: Wiesbaden, Germany, 2020; pp. 89-91. ISSN 2524-4809.

17. Fleck, C.; Eifler, D. Corrosion, fatigue and corrosion fatigue behaviour of metal implant materials, especially titanium alloys. Int. J. Fatigue 2010, 32, 929-935. [CrossRef]

18. Magnin, T. Recent Advances for Corrosion Fatigue Mechanisms. ISIJ Int. 1995, 35, 223-233. [CrossRef]

19. Roeder, E.; Selzer, R.; Vollmar, J. Elektrochemisch kontrollierte Dauerschwingversuche mit dem ferritisch-austenitischen Stahl X2CrNiMoN 2253 in 3 \%iger NaCl-Lösung. Steel Res. 1991, 62, 459-464. [CrossRef]

20. Tada, E.; Noda, K.; Kumai, S.; Tsuru, T. Monitoring of corrosion fatigue cracking using harmonic analysis of current responses induced by cyclic stressing. Corros. Sci. 2004, 46, 1549-1563. [CrossRef]

21. Wittke, P.; Klein, M.; Dieringa, H.; Walther, F. Corrosion fatigue assessment of creep-resistant magnesium alloy Mg-4Al-2Ba-2Ca in aqueous sodium chloride solution. Int. J. Fatigue 2016, 83, 59-65. [CrossRef]

22. Wittke, P.; Klein, M.; Walther, F. Corrosion Fatigue Behaviour of Creep-resistant Magnesium Alloy Mg-4Al-2Ba-2Ca. Procedia Eng. 2014, 74, 78-83. [CrossRef]

23. Rosskamp, M.; Albrecht, N.; Ilg, U.; Neder, H.; Reitzner, U.; Riedmüeller, B.; Rutschow, D. VGB guideline for the water in nuclear power plants with light water reactor (BWR) VGB-R 401 J. Powertech 2007, 87, 73-79.

24. Chopra, O.K.; Shack, W.J. Effect of LWR coolant environments on the fatigue life of reactor materials. In Proceedings of the ASME 2006 Pressure Vessels and Piping/ICPVT-11 Conference, Vancouver, BC, Canada, 23-27 July 2006; pp. 191-204. [CrossRef]

25. Weißenberg, T. Zentrale Untersuchung und Auswertung von Herstellungsfehlern und Betriebsschäden im Hinblick auf Druckführende Anlagenteile von Kernkraftwerken, Arbeitspaket 3, Einfluss des Reaktorkühlmediums auf das Ermüdungsverhalten Austenitischer Rohrleitungen; BMU-Vorhaben SR 2501; MPA Universität Stuttgart: Stuttgart, Germany, 2007. 
26. Maci, F.; Jamrozy, M.; Acosta, R.; Starke, P.; Boller, C.; Heckmann, K.; Sievers, J.; Schopf, T.; Walther, F. Characterization of the fatigue behavior of mechanical and thermal aged austenitic power plant steel AISI 347. In Mechanical Fatigue of Metals, Structural Integrity 7; Correia, J., De Jesus, A., Fernandes, A., Calçada, R., Eds.; Springer Nature Switzerland AG: Cham, Germany, 2019; pp. 65-71.

27. Morrow, J.D. Cyclic plastic strain energy and fatigue of metals. In Internal Friction, Damping and Cyclic Plasticity; ASTM International: West Conshohocken, PA, USA, 1964; pp. 45-87.

28. Basquin, O.H. The exponential law on endurance tests. Am. Soc. Test. Mater. 1910, 10, 625-630.

29. Manson, S.S. Fatigue: A complex subject-Some Simple approximations. Exp. Mech. 1965, 5, 193-226. [CrossRef]

30. Starke, P.; Eifler, D.; Boller, C. Fatigue assessment of metallic materials beyond strain measurement. Int. J. Fatigue 2016, 82, 274-279. [CrossRef]

31. Heckmann, K.; Sievers, J.; Schopf, T.; Lücker, L.; Schmiedt-Kalenborn, A.; Walther, F.; Starke, P.; Acosta, R.; Boller, C. Correlation of load drop and crack initiation criteria in fatigue life experiments of metallic materials. Eng. Fract. Mech. 2021, $251,107785$. [CrossRef]

32. Müller-Bollenhagen, C. Verformungsinduzierte Martensitbildung bei Mehrstufiger Umformung und Deren Nutzung zur Optimierung der HCF- und VHCF-Eigenschaften von austenitischem Edelstahlblech. Ph.D. Thesis, Universität Siegen, Siegen, Germany, 2011.

33. Shack, W.J.; Kassner, T.F. Review of Environmental Effects on Fatigue Crack Growth of Austenitic Stainless Steels; Technischer Bericht NUREG/CR-6178 ANL 94/1; U.S. Department of Energy Office of Scientific and Technical Information, Argonne National Lab.: Lemont, IL, USA, 1994. [CrossRef]

34. Platts, N.; Tice, D.R.; Zhang, W. Negative load ratio fatigue crack growth rate testing on austenitic stainless steel in a simulated primary water environment. In Proceedings of the ASME Pressure Vessels and Piping Conference, Boston, MA, USA, 19-23 July 2015. 